\title{
O Sociopsicodrama e a Reabilitação Psicossocial de Pessoas em Situação de Dependência Química: Desenvolvendo Novos Papéis
}

\author{
Jéssica Gomes May ${ }^{l}$; Amanda Castro ${ }^{2}$
}

\begin{abstract}
Resumo: Considerando que a dependência química está entre os problemas sociais que mais crescem no Brasil e no mundo, esta pesquisa teve como foco a reabilitação psicossocial de pessoas em situação de dependência química, usuárias do Centro de Atenção Psicossocial para Álcool e outras Drogas - CAPS II AD. Um dos objetivos desta pesquisa foi proporcionar aos participantes o desenvolvimento de novos papéis, para empoderá-los na busca pela reabilitação psicossocial a partir das contribuições do sociopsicodrama. Foram realizados oito encontros, formados por quatro integrantes do sexo masculino, com idades entre 37 e 46 anos.
\end{abstract}

Palavras-chave: Sociopsicodrama; dependência química; papéis.

\section{Sociopsicodrama in the Psychosocial Rehabilitation of People in the Situation of Chemical Dependence: Developing New Roles}

\begin{abstract}
This research focused on the use of sociopsicodrama for the psychosocial rehabilitation of people in situations of chemical dependence, users of the Psychosocial Care Center for Alcohol and other Drugs. Eight meetings were held, with four men between 37 and 46 years old. Among the results obtained it is possible to highlight: a) The importance of rescuing memories and experiencing childhood moments in the supplementary reality; b) the sociopsicodrama can decristalize the masks that prevent them from seeing new possibilities of active and committed action in their life; c) the projection technique for the future allowed to stimulate more appropriate contacts with the other and reality; d) The sociopsicodrama allows the construction of a new role, the "I of the future".
\end{abstract}

Keywords for this page: Drug; Alcohol; Psychodrama.

\footnotetext{
${ }^{1}$ Psicóloga. Graduada em Psicologia na Universidade do Extremo Sul Catarinense - UNESC. jeh.may@ hotmail.com;

2 Doutoranda em Psicologia pelo Programa de Pós Graduação da Universidade Federal de Santa Catarina. Mestre em Psicologia. Psicodramatista formada pela escola Viver Psicologia Psicodrama. Especialista em Psicodrama pelo Centro Universitário Amparense - Unifia. Especialista em Psicologia do desenvolvimento pela Universidade de Araraquara UNIARA. Psicóloga formada pela Universidade do Sul de Santa Catarina. Professora na Universidade do Extremo Sul Catarinense - Unesc e no Curso de Formação em Práticas de grupo e Especialização em Psicodrama na Escola Viver Psicologia: psicodrama. amandacastrops@gmail.com.
} 


\section{Introdução}

A espiritualidade dentro do contexto da saúde mental está tomando cada vez mais espaço. Entre os serviços que compõem a Rede de Atenção Psicossocial (RAPS), há os Centros de Atenção Psicossocial (CAPS). Através da portaria no 336 de 19 de fevereiro de 2002, foi criado pelo Ministério da Saúde, o Centro de Atenção Psicossocial para Álcool e outras Drogas (CAPS AD). Esta rede de serviços é destinada ao atendimento integral de pessoas com problemas relacionados ao uso abusivo de álcool e outras drogas (CREPOP, 2013).

O Relatório Brasileiro sobre Drogas (2009) informa que, no ano de 2007, 138.585 internações foram efetivadas, cujo diagnóstico principal foi algum transtorno mental e comportamental causado pelo uso de drogas. Segundo Dalgalarrondo (2000), droga psicoativa é toda e qualquer substância química que modifica funções do Sistema Nervoso Central, causando efeitos psíquicos e comportamentais.

No que diz respeito aos aspectos sociais e psicológicos da dependência química, Cunha (2012) destaca que o uso de drogas é um sintoma de mal-estar na vida do sujeito, carregando consigo um apelo sobre algo de si mesmo e do grupo social em que vive, tanto relacional quanto cultural. Com o uso da substância, o indivíduo passa de um estado de ser ou sentir-se menos para um sentimento muito melhor, nem que seja por um determinado tempo, construindo com a droga a relação dos super-heróis com seus superpoderes (Cunha, 2012).

O papel, segundo Moreno (1975), pode ser definido como uma fusão de elementos privados, sociais e culturais, resultando em uma síntese de experiências. O termo papel é utilizado no sociopsicodrama como unidade de representação teatral e de ação, e como funções sociais, assim como o conceito de papel está relacionado com todas as dimensões da vida, utilizando a existência como experiência individual e modo de participação na sociedade (Gonçalves, Wolff, \&Almeida, 1988).

As reflexões propostas por esta pesquisa se referem ao papel do psicólogo no contexto da dependência química, com usuários do Centro de Atenção Psicossocial para Álcool e outras Drogas - CAPS II AD, através do Sociopsicodrama, que representa um instrumento importante na intervenção social. Para Morin e Hadler (2013), o sociopsicodrama é a ação dramática trabalhada em grupo que visa trabalhar aspectos sociais, desenvolvendo a espontaneidade e a criatividade enfraquecidas em cada indivíduo que busca o apoio para a reabilitação psicossocial. 
Os dependentes químicos e seus familiares, segundo Kellermann e Hudgins (2010), acabam sofrendo algum tipo de dano psicológico devido ao uso da substância tóxica, e por este motivo o método sociopsicodramático pode ajudar o dependente químico a adquirir controle e domínio sobre a sua vida, além de viver experiências que proporcionem reparações de papéis e padrões de relacionamentos.

No âmbito social e familiar, o indivíduo passa a ser visto unicamente através do papel de dependente químico, e apesar de anestesiá-lo diante das múltiplas exigências e pressões, o não reconhecimento destes aspectos sociais e psicológicos da pessoa em situação de dependência pode deixá-lo na categoria do fracasso e da exclusão (Cunha, 2012). Considerando os aspectos psicológicos, sociais e familiares, surge a necessidade de identificar como o sociopsicodrama pode contribuir para o desenvolvimento de novos papéis para pessoas em situação de dependência química, para além do papel de dependente.

\section{Metodologia}

Este estudo tratou-se de uma pesquisa qualitativa, descritiva e exploratória, na modalidade pesquisa-ação. A amostra foi composta por um grupo de quatro usuários do Centro de Atenção Psicossocial para Álcool e outras Drogas - CAPS II AD da cidade de Criciúma, do sexo masculino, com idades entre 37 e 46 anos, residentes em Criciúma ou região. Foram realizados oito encontros semanais (de aproximadamente $1 \mathrm{~h} 30 \mathrm{~min}$ cada sessão), com temas previamente programados, no período entre agosto e outubro de 2017. Os instrumentos utilizados foram: protagonista, diretor, ego-auxiliar, público e cenário (Gonçalves, Wolff, \&Almeida, 1988). Para este relato de experiência foi analisada a sexta sessão, por atender ao objetivo de identificar a contribuição do Sociopsicodrama para o desenvolvimento de novos papéis para pessoas em situação de dependência química, para além do papel de dependente.

\section{Resultados e discussão}

Os resultados da pesquisa foram divididos em duas etapas visando apresentar uma 
análise individual mais clara dos dados obtidos através do BDI (2011) e do A sexta sessão teve como objetivo buscar a clarificação dos papéis e suas atribuições, além de possibilidades de reflexão acerca dos projetos futuros. Compareceram ao encontro três participantes, cujos nomes utilizados foram fictícios: Paulo (46 anos), Roberto (37 anos) e Fernando (44 anos). Inicialmente foi realizado os aquecimentos através da utilização de estímulos sonoros com melodia que facilitaria o relaxamento dos participantes para melhor concentração nas consignas dadas pela pesquisadora, levando-os a pensar em sua história de vida até a transição para a vida adulta. Para Guimarães (1998), ao utilizar a fonte de estímulo auditivo, deve-se considerar a complexibilidade em termos de aquecimento e conteúdo que poderá emergir a partir deste estímulo musical, seja através de ritmos ou melodias.

Para a dramatização, foi realizada a técnica do psicodrama interno em paralelo com a projeção para o futuro, em que a pesquisadora conduziu os participantes através de consignas a encontrarem o "eu do passado" e com o "eu do futuro". De acordo com Cukier (1992) esta técnica, tem como objetivo sensibilizar o indivíduo a recuperar momentos do seu passado confrontando com o presente, além de trabalhar conflitos internos ou pessoas com quem tem algo a resolver.

Em um primeiro momento, os participantes foram conduzidos a voltarem ao passado e se encontrarem com o "eu do passado" aos sete anos de idade. Foi orientado que cada participante prestasse atenção nas características desta criança e no que ela gostaria de lhe falar. Em seguida, foram conduzidos ao futuro, encontrando consigo mesmo na velhice e orientados a ouvir o conselho que seu "eu do futuro" lhe daria. De acordo com Cukier (1992, p. 85), "é importante que as consignas sejam dadas de forma pausada e suave e que o terapeuta vá sentindo o nível de emoção despertado".

Inicialmente, a dramatização foi conduzida pensando na possibilidade de ocorrência de um sociodrama, mas posteriormente desencadeou-se um Psicodrama. De acordo com Almeida (2010, p. 93), "no psicodrama, a abordagem envolveria a catarse pessoal. No sociodrama, o sujeito não é a pessoa e, sim, o grupo". Deste modo o Sociopsicodrama revela sua flexibilidade durante os grupos psicoterapêuticos, pois mesmo diante da expectativa do aquecimento, a direção da sessão é compartilhada com o protagonista, sendo ele quem aponta os caminhos (Castro \& Almeida, 2017).

Ao relatar sua experiência, Fernando referiu que sua criança estava triste e que não 
conseguiu visualizar a si mesmo no futuro, encontrando apenas seu pai, que se mostrou decepcionado e triste com o filho. Houve então o surgimento de um emergente protagônico no grupo, surgindo a necessidade trabalhar o bloqueio na projeção de si mesmo para o futuro e as tentativas de suprir as expectativas do pai.

Em cena, Fernando assumiu o papel de seu pai já falecido, selecionou Paulo para representá-lo no presente e a pesquisadora para representar seu "eu do passado". O pai, triste, relata que imaginou uma vida diferente para o filho e que se sente culpado por sempre apoiá-lo e não o repreender. O ego-auxiliar no papel de Fernando referiu sentimento de culpa e fracasso, pois causou frustração em todos ao seu redor, inclusive ao "eu do passado". Segundo Gonçalves (1998), o ego-auxiliar é capaz de captar as emoções e sentimentos do protagonista no momento em que apresenta dificuldade ou impossibilidade de se expressar, e verbaliza por ele, tornando o protagonista espectador de si mesmo. Em seguida, foi realizada a inversão de papéis, em que Fernando ocupou seu próprio papel e dialogou com seu pai, conforme descrito abaixo:

Pai: "Como me dói te ver nessa situação, assim cabisbaixo, envergonhado. Eu não queria te ver assim, te criei com tanto amor [..] Me diz o que eu errei?

Fernando: Bom pai, na realidade o que o senhor errou foi que tudo que eu queria o senhor me dava. Mas conversava pouco comigo sabe, não parava um pouco para me ouvir.

Pai: Então eu me fazia presente na tua vida com as coisas que eu te dava, e não com o que eu dizia? Mas então porque você está se sentindo culpado?

Fernando: Não sei, sinceramente eu não sei.

Pai: Se a culpa é minha porque você está se sentindo culpado? A culpa é minha?

No momento em que o ego-auxiliar no papel do pai fez a pergunta "a culpa é minha?", Fernando permaneceu em silêncio, e após ouvir a pergunta pela terceira vez, respondeu:

Fernando: A culpa não é do senhor. A culpa é minha. Eu que fui o responsável por tudo que aconteceu comigo.

Pai: E por isso que tu tens vergonha?

Fernando: Eu me sinto frustrado por não ter te dado um retorno. 
Ao aprofundar o diálogo a respeito das expectativas do pai, buscou-se a compreensão da projeção da imagem do pai para o seu futuro:

Pai: Você me vê triste, porque você tá triste. Por isso que você não sabia se via você ou eu aqui. Tá uma confusão porque a gente tá triste, eu e você. Aí teve o bloqueio.

Fernando: Realmente. Eu me sinto culpado e triste sabe, aí eu fico agarrado na culpa e no passado. Eu tenho que me desprender disso aí, senão o futuro vai ser sempre tristeza.

Fernando (ego-auxiliar): Pai, eu sei que o senhor fez de tudo para mim [...], o senhor nunca falou o que esperava de mim, mas eu sei. Mas eu tenho que te dizer uma coisa pai, eu não sou obrigado a ser o que você quer.

Fernando percebeu que via as expectativas do pai em relação a ele de maneira equivocada, afirmando que o que faz seu pai feliz é vê-lo bem. Segundo Nery (2014), o indivíduo aprende emoções e condutas relacionadas ao papel complementar interno patológico, que se tornarão conteúdos da sua criança interna ferida, conduzindo-o a alguns autoconceitos, desenvolvendo lógicas afetivas de conduta. No caso do protagonista Fernando, a possível lógica afetiva de conduta identificada durante o ato psicodramático foi "Como não consigo ser o que meu pai gostaria, eu não serei nada".

Ao retornar para o papel do pai, o participante afirmou: "Eu sempre me preocupei contigo. Tu me conhece, eu sou uma pessoa fechada, não consigo transmitir o amor que sinto por ti. E você também sempre foi fechado".

Fernando (ego-auxiliar): Faltou eu perguntar o que tava acontecendo de verdade, aí eu ficava imaginando o que as pessoas esperavam de mim [...] Eu fico tão preocupado com isso que esqueço que preciso agir, que preciso tentar.

Eu do passado: Apesar de você ter me visto triste, eu não era triste. Você olha para trás e não consegue mais ver como eu sou feliz [...] essa vontade de aprender e de viver ainda tá dentro de você. Só falta resgatar.

Percebeu-se que a culpa que Fernando sente não o deixa ver o que as pessoas sentem por ele, o que o faz olhar para trás e ver sua criança triste, olhar para seu pai e vê-lo triste. A 
busca incessante por voltar a ser quem era antes da dependência química, o impede de viver o presente e agir na tentativa de melhorar sua vida, o que segundo Rigotto e Gomes (2002) favorece o ciclo da dependência. Foi ressaltada a importância de resgatar aspectos que considera importante para a sua vida, porém como não há como voltar no tempo, se faz necessária a reconstrução e ressignificação destes aspectos a partir do que se tornou.

Ao final da técnica, Fernando referiu que o semblante de seu pai mudou, mostrando-se mais alegre, e com um abraço despediu-se dele, afirmando que o ama. Silva Filho (2011, p. 229), afirma que "um dos objetivos do psicodrama e das psicoterapias de grupo é estimular contatos mais adequados com o outro e com a realidade, construindo relações mais satisfatórias, baseadas na ampliação do campo de escolhas próprias e da responsabilidade".

$\mathrm{Na}$ fase do compartilhar, Fernando concluiu: "Não tem como eu voltar a ser quem eu era antes. Eu tenho que resgatar a essência, mas não quero voltar atrás, quero ser uma pessoa nova daqui para frente". Pode-se perceber através da fala deste participante que houve a construção de um novo papel, o “eu do futuro". Quando há um treinamento de papel através do método utilizado, é chamado de role-playing, que segundo Moreno (1975, p. 413-414), "é personificar outras formas de existência, por meio do jogo". Desenvolver novos papéis é essencial para que o indivíduo não cristalize em apenas um: no caso o de pessoa em situação de dependência química.

\section{Considerações Finais}

Dentre os resultados obtidos e considerando os objetivos deste trabalho é possível destacar que a técnica de projeção para o futuro permitiu estimular contatos mais adequados com o outro e com a realidade, construindo relações mais satisfatórias, considerando livre arbítrio e responsabilidade. Percebeu-se também que o sociopsicodrama permite a construção de um novo papel, o "eu do futuro". Propiciando, portanto, que o grupo explorasse mais papéis, para além do papel de dependente. A partir do desempenho de papéis foi possível perceberem a possibilidade de modificarem o contexto e a si mesmos. 


\section{Referências}

Almeida, W. C. D. (2010). Além da catarse, além da integração, a catarse de integração. Revista Brasileira de Psicodrama, 18(2), 97-106.

Castro, A., \& Almeida, V. (2017). O psicodrama de grupo ea ressignificação de sentimentos: o adolescente no palco. Revista Brasileira de Psicodrama, 25(1), 101-107. Doi:

10.15329/2318-0498.20170012.

CREPOP, Centro de Referência Técnica em Psicologia e Políticas Públicas. Referências Técnicas para atuação de Psicólogas (o) em Políticas Públicas de Álcool e Outras Drogas. (2013). Brasília: Conselho Federal de Psicologia (CFP). Disponível em: <http://crepop.pol.org.br/novo/wp-

content/uploads/2013/12/CREPOP_REFERENCIAS_ALCOOL_E_DROGAS_FINAL_10.01 .131.pdf>. Acesso em: 15 jan. 2018.

Cukier, R. (1992). Psicodrama bipessoal. São Paulo:Editora Agora.

Cunha, A. C. M. (2012). O consumo de drogas: Drug-use. Revista Brasileira de Psicodrama, 20(1), 197-202.

Dalgalarrondo, P. (2018). Psicopatologia e semiologia dos transtornos mentais. São Paulo: Artmed Editora.

Duarte, P.; Stempliuk, V.; Barroso, L. (2009). Relatório brasileiro sobre drogas. Secretaria Nacional de Políticas sobre Drogas. Brasília: SENAD. Disponível em:<http://justica.gov.br/central-de-conteudo/politicas-sobre-drogas/relatorios-politicassobre-drogas/relatoriobrasileirosobredrogas-2010.pdf>. Acesso em: 05 dez. 2017.

Gonçalves, C. S., Wolff, J. R., \& de Almeida, W. C. (1988). Lições de psicodrama: introdução ao pensamento de JL Moreno. São Paulo: Editora Agora.

Gonçalves, C. S.(1998) Técnicas básicas: duplo, espelho e inversão de papéis. In: Monteiro, R. F (org). Técnicas fundamentais do psicodrama. São Paulo: Editora Agora.

Guimarães, L. A. A música no psicodrama: um caminho para atualizar a cena. (1998)

Campos do Jordão Disponível em:

http://www.asbap.com.br/producao/musica_no_psicodrama.pdf>. Acesso em: 05 dez. 2017.

Kellermann, P. F., \& Hudgins, M. K. (2010). Psicodrama do trauma: o sofrimento em cena. São Paulo: Ágora.

Moreno, J. L. (1978). Psicodrama. São Paulo: Editora Cultrix. 
Morin, P. V., \& Hadler, O. H. (2013). Mosaico de vidas: reflexões sobre sociopsicodramas na saúde coletiva. Revista Brasileira de Psicodrama, 21(1), 55-66.

Nery, M. D. P. (2003). Vínculo e afetividade: caminhos das relações humanas. São Paulo: Ágora.

Rigotto, S. D., \& Gomes, W. B. (2002). Contextos de abstinência e de recaída na recuperação da dependência química. Psicologia: teoria e pesquisa. Brasília. Vol. 18, n. 1 (jan./abr. 2002), p. 95-106.

Silva Filho, L. A. (2011). Doença mental, um tratamento possível: Psicoterapia de grupo e psicodrama. Editora Agora.

\section{Como citar este artigo (Formato ABNT):}

MAY, Jéssica Gomes; CASTRO, Amanda Castro. O Sociopsicodrama e a Reabilitação Psicossocial de Pessoas em Situação de Dependência Química: Desenvolvendo Novos Papéis. Id on Line Rev.Mult. Psic., 2018, vol.12, n.42, p. 515-523. ISSN: 1981-1179.

Recebido: 02/10/2018;

Aceito: 04/10/2018 